\title{
Somatostatin analogue octreotide and inhibition of tumour growth in metastatic endocrine gastroenteropancreatic tumours
}

\author{
R Arnold, M E Trautmann, W Creutzfeldt, R Benning, M Benning, C Neuhaus, \\ R Jürgensen, K Stein, H Schäfer, C Bruns, H-J Dennler, and the German Sandostatin \\ Multicentre Study Group
}

Abstract

Antiproliferative treatment of patients with metastatic endocrine gastroenteropancreatic tumours (GEP) is based mainly on chemotherapeutic protocols whereby drug toxicity is a major handicap. Octreotide is the first choice in the control of hormone mediated symptoms. From retrospective and a few prospective studies it has been suggested that octreotide exhibits antiproliferative properties. The prospective German Sandostatin multicentre phase II trial investigated the effects of $200 \mu \mathrm{g}$ octreotide thrice daily for one year on tumour growth and endocrine abnormalities in 103 patients. Octreotide treatment was continued in those patients responding to the drug until tumour progression occurred. In 28 of those with tumour progression during $200 \mu \mathrm{g}$ thrice daily octreotide dose was increased to $500 \mu \mathrm{g}$ thrice daily. The study sample consisted of 52 patients with computed tomography confirmed tumour progression and 13 patients with stable disease before octreotide treatment, whereas no preobservation period was available in 38 patients. Nineteen patients $(36.5 \%)$ with computed tomography confirmed tumour progression experienced stabilisation of tumour growth lasting for at least three months. Median duration of stable disease was 18 months. At month 12, stable disease continued in 12 patients, declined after 24 months to nine patients, and after 36 months to five patients. Tumour regression has not been seen in this or other subgroups. In the subgroup with stable disease before octreotide, stable disease continued in $53.8 \%$ of patients over 12 months. Increase of octreotide dose to $500 \mu \mathrm{g}$ thrice daily did not influence progression seen during the lower dose with the exception of one patient in whom tumour progression changed to stable disease. No association of tumour size response and patients' characteristics could be detected. The results suggest that octreotide inhibits tumour growth in patients with metastasised endocrine GEP tumours. The antiproliferative effect is, at least in some patients, longlasting. Currently, octreotide can only be recommended as an antiproliferative drug if patients with clearly progressive disease show stabilisation after treatment for three to six months.

(Gut 1996; 38: 430-438)

Keywords: octreotide, endocrine tumours, tumour growth inhibition, symptomatic response, side effects.

In patients with metastatic endocrine gastroenteropancreatic (GEP) tumours definite healing of the disease cannot be achieved by the currently available therapeutic strategies. In the treatment of patients with metastatic GEP tumours, however, it is important to note that even in fast growing tumours control of hormone mediated symptoms improves or, at least normalises, the quality of life. ${ }^{1-6}$ Spontaneous tumour growth varies from one patient to another with tumours and metastases remaining unchanged in size for months or even years without treatment, tumours growing slowly and independently on any antiproliferative measures, and tumours showing explosive growth. ${ }^{7}$ Aggressive antiproliferative strategies are only desired in the last of these tumours and in patients whose severity of associated endocrine syndrome is unresponsive to less harmful therapeutic measures. In principle, antiproliferative strategies include surgical tumour debulking, ${ }^{8}$ hepatic artery embolisation, ${ }^{910}$ chemotherapy ${ }^{11-16}$ and, in selected patients with liver metastases, liver transplantation. ${ }^{17}$ Recently, a multicentre trial has presented encouraging results from patients with metastatic islet cell carcinoma responsive to the combination of streptozotocin and doxorubicin in terms of the rate of tumour regression, the length of time to subsequent tumour progression, and survival if compared with the standard regimen of streptozotocin plus fluorouracil. ${ }^{16}$ Toxic reactions, however, including severe bone marrow suppression, nephrotoxicity, and heart failure have been seen in a substantial percentage of these patients. ${ }^{16}$ In contrast, anaplastic neuroendocrine carcinomas, an entity characterised histologically by a less well developed neuroendocrine pattern and greater mitotic activity, explosive tumour growth, and less frequent clinically recognisable excess hormone production ${ }^{18}$ responded well in a significant percentage to the combination of etoposide and cisplatin, whereas patients with well differentiated carcinoid tumours did not. ${ }^{15}$ Again, drug toxicity was an important problem in 
this study. These studies clearly show, however, that subgroups of patients with metastatic endocrine GEP tumours may benefit from specific chemotherapeutic protocols whereas other subgroups fail. Therefore, alternative therapeutic strategies would be greatly desired particularly if they prove to be less compromising to the patient's quality of life compared with systemic chemotherapy. Currently, interferon alpha, ${ }^{19-21}$ longacting somatostatin analogues, ${ }^{722} 23$ and combinations ${ }^{24-26}$ are under investigation with respect to their antiproliferative potencies, but because of the low incidence of the disease available data are based on small numbers of patients. The longacting somatostatin analogue octreotide is currently the therapeutic principle of first choice to control reliably flushing, wheezing, and diarrhoea in patients with carcinoid syndrome, ${ }^{62728}$ watery diarrhoea in patients with Verner-Morrison syndrome, ${ }^{629-31}$ and the necrolytic migratory erythema in patients with glucagonoma syndrome. ${ }^{32}$ Evidence for additional antiproliferative properties arise from in vitro data using tumour cell lines, from animal models with solid tumours, ${ }^{33}$ and from case reports in humans describing even tumour regression in patients with metastatic endocrine GEP tumours. ${ }^{6}{ }^{34-38}$ According to an NIH report summarising data from retrospective studies, the size of metastases decreased in $13 \%$ of 94 patients, tumour size remained unchanged in $63 \%$ whereas in $24 \%$ tumour progression was not influenced by octreotide. ${ }^{22} \mathrm{~A}$ phase II trial on 34 patients with advanced neuroendocrine tumours using a median dose of $250 \mu \mathrm{g}$ octreotide three times daily and including only patients with clear objective progression before the start of treatment reported a stabilisation of the disease in 50\% lasting from 2-27 months, but no major objective tumour regressions were seen. ${ }^{23}$

This report describes the results of the German Sandostatin multicentre phase II trial on the effect of octreotide on tumour growth and endocrine abnormalities in 103 patients with metastatic endocrine GEP tumours. Our interest was focused on patients with confirmed tumour progression before the onset of octreotide therapy. We hypothesised that a potentially antiproliferative effect of octreotide depends on variables including patient's Karnofsky index, tumour growth behaviour before octreotide therapy, the presence or

TABLE I Characteristics of the 103 study patients

\begin{tabular}{ll}
\hline Median age (y) (range) & $56(26-78)$ \\
Male/female & $54 / 49$ \\
Functional tumours & 64 \\
Non-functional tumours & 39 \\
Time from diagnosis to study entry (median & \\
month) (range) & $17(1-251)$ \\
Karnofsky status at study entry & 5 \\
$<50$ & 42 \\
$50-70$ & 53 \\
$80-100$ & 3 \\
No information & 21 \\
Previous antiproliferative treatment & 9 \\
Chemotherapy & 2 \\
Interferon alpha & 4 \\
Hepatic artery embolisation & \\
Combinations & \\
\hline
\end{tabular}

absence of octreotide receptors on the tumour, the secretory activity of the tumour, and the ability of octreotide to suppress hormone mediated symptoms.

\section{Methods}

\section{Patient population}

The patients enrolled in this prospective multicentre trial were cared for at 49 different hospitals in Germany. All had advanced, incurable endocrine GEP tumours with histological proof by pathological review at our institution. Patients with active hormone production confirmed by blood or urine measurement and the presence of a typical clinical syndrome were classified as having a functional carcinoid or islet cell tumour. Patients with no demonstrable hormone production and no hormone mediated symptoms were classified as having non-functional endocrine GEP tumours even if the tumour cells showed, in addition to general neuroendocrine markers, cell specific markers as serotonin or substance P. ${ }^{39}$ Patients with functional or non-functional poorly differentiated intermediate or small cell carcinoma with high grade malignant behaviour ${ }^{39}$ have not been included. All major west and a few east German university and city hospitals received an information letter describing design and aim of the trial. Upon request, 167 registration forms were sent between March 1989 and September 1991 from the study office to hospitals expressing interest in participating in the study. Study medication was only provided after registration forms were received in the study office. Patients with confirmed tumour progression within the preceding six months and those with endocrine symptoms requiring octreotide therapy and showing a measurable indicator of response to treatment with computed tomography were regarded as eligible for participation. Pregnancy, patients receiving octreotide before study entry, and those with no measurable indicator with computed tomography were excluded. The Karnofsky performance score, previous chemotherapy, treatment with interferon alpha, hepatic artery embolisation, and combinations of these strategies were not criteria for exclusion (Table I).

Pretreatment evaluation included a complete medical history and physical examination, complete blood count, biochemical screening profile, chest radiography, and computed tomography of pertinent indicator lesions. Hormone markers showing the functional status of the tumour were obtained at the start of octreotide therapy and repeated after six weeks and every three months until discontinuation of the treatment. Appropriate hormone markers included serum gastrin concentrations in patients with gastrinoma, serum glucagon in patients with glucagonoma syndrome, serum insulin in metastatic insulinoma and 24 hour urinary 5-hydroxyindoleacetic acid (5-HIAA) in patients with carcinoid syndrome. 


\section{Treatment}

The study protocol was approved by the Ethics Committee of the Medical Faculty of the Philipps-University, Marburg. All patients gave informed consent to the study.

Octreotide (SMS 201-995) provided by Sandoz, Nürnberg, Germany was given by subcutaneous injection. Treatment was started at an initial test dose of $50 \mu \mathrm{g}$ thrice daily for three days, increased to $100 \mu \mathrm{g}$ thrice daily for three days, and to $200 \mu \mathrm{g}$ thrice daily from day 7. This octreotide dose seemed rather high in 1989 and concern was formulated that receptor down regulation could be the consequence of this dose. As $200 \mu \mathrm{g}$ octreotide thrice daily effectively suppresses hormone secretion from endocrine GEP tumours, we assumed that this dose could also mediate antiproliferative action. Treatment was continued for at least six months and stopped if disease progression was noted by computed tomography at two subsequent follow up periods. Some of the participating centres decided to increase the octreotide dose to $500 \mu \mathrm{g}$ thrice daily for at least six months in a total of 28 patients with ongoing tumour progression with the lower dose. According to the study protocol the trial was intended to last for 12 months. Therefore, responders to continued octreotide therapy were evaluated after 12 months, but subjected to further follow ups during the subsequent 42 months. Patients with gastrinoma received 40-60 $\mathrm{mg}$ oral dose of omeprazole daily in addition to octreotide. During octreotide treatment patients did not receive other antiproliferative therapy, either chemotherapy or interferon alpha. Supplementation of pancreatic enzymes was permitted whenever steatorrhoea was present or changes in bowel habits developed suggestive of malabsorption during octreotide therapy.

\section{Evaluation of response}

Follow up investigations were performed in three month intervals for one year and included physical examination, complete blood count, biochemical screening profile, hormones, and assessment of tumour growth as during pretreatment examination. For evaluation of clinical symptoms each patient kept a diary regarding number, extent and severity of flushing, frequency and consistency of bowel movements, and grading of their well being. In patients responding to treatment with growth inhibition follow up visits were extended to six month intervals after the first year.

Tumour growth was assessed by computed tomography of pertinent indicator lesions in a blind fashion without knowledge of the clinical data. Eighty nine of 103 patients had measurable disease in the liver. Number of metastases within the liver, ligament hepatoduodenale, mesenterium, periaortic lymphnodes or elsewhere was estimated as well as the size of two to three reference metastases and of an unresectable primary determined by measuring the respective perpendicular diameters. Planimetry during ultrasound and volumetry of computed tomography confirmed reference metastases was performed if possible. In seven patients the liver parenchyma was diffusely infiltrated by the tumour. Therefore, other criteria such as total liver size and newly developed ascites indicating peritoneal carcinosis seen in two patients with intestinal carcinoids have been used for follow up investigations.

In the study protocol progression was defined as an increase in tumour growth by more than $25 \%$ within three months assessed by multiplication of the length of two perpendicular diameters estimated in at least two different metastases or by the appearance of new metastases. Tumours growing slowly but continuously with progression of less than $25 \%$ within three months were also judged as 'progression' if progression of more than $25 \%$ occurred within the observation period of 12 months.

Stable disease was assumed if increase or decrease in tumour size of less than $25 \%$ was seen within the observation period.

Partial regression was defined as decrease in tumour size by more than $50 \%$ within the observation period.

Response to octreotide was defined as stable disease or decrease in tumour growth after confirmed progression before treatment or decrease in tumour growth after stable disease within the pretreatment period, if lasting for at least three months.

No assessment was possible if growth behaviour before octreotide was unknown, but showed stable disease during octreotide treatment. All patients with progression of tumour growth during octreotide treatment were considered as non-responders. Escape from initially successful treatment was defined as progression of tumour growth after ascertained response to octreotide for at least three months.

In terms of the hormonal assay, response to octreotide was defined as a decrease of at least $50 \%$ compared with pretreatment values and a duration of response for at least three months. Non-responders were those with less than $50 \%$ improvement and a duration of response for less than three months.

\section{Somatostatin receptor status}

Somatostatin receptors were visualised either in vitro by somatostatin receptor autoradiography using SDZ 204-090, the stable $\mathrm{Tyr}^{3}$ analogue of SMS 201-995 as specific radioligand ${ }^{40}$ or by in vivo scintigraphy using indium labelled octreotide (Octreoscan 111; Mallinckrodt Diagnostika, the Netherlands). ${ }^{41}$

\section{Side effects}

Patients were evaluated with respect to general clinical unspecific side effects and to the development of diarrhoea (more than three loose stools not present before), flatulence, nausea, vomiting, and pain at injection site. The diagnosis of gall stones was based on gall bladder ultrasound before study entry and at follow up investigations every three months during the study. Hyperglycaemia was assumed as side 
effect of octreotide therapy if fasting blood glucose concentrations were $<90 \mathrm{mg} \%$ before study entry but increased above $120 \mathrm{mg} \%$ during octreotide treatment. Faecal fat excretion was evaluated in 28 patients investigated at the hospital of the study centre and steatorrhoea was assumed if total stool fat exceeded $7 \mathrm{~g} / 24 \mathrm{~h}$.

\section{Statistical analysis}

Descriptive statistical methods have been applied to describe frequencies, medians, and ranges. According to the study protocol, the group of patients with computed tomography confirmed progression, stable disease, and no information on spontaneous tumour growth before octreotide treatment have been analysed separately. Additional subgroup analysis was performed in the subgroup with confirmed tumour progression before octreotide treatment. $\chi^{2}$ Tests were used for descriptive purposes only.

To visualise the time of growth inhibition in response to octreotide to further tumour progression, the number of patients with growth inhibition was plotted over the time axis. In Fig 2 timepoint 0 corresponds to the follow up visit, when growth inhibition was first confirmed. Further progression after computed tomography confirmed growth inhibition was assumed to have occurred in the middle of the preceding time interval. Analysis of side effects was based on the total study sample of 96 patients.

\section{Inclusion according to the decision of the participating hospitals}

\section{Retrospective computed tomography evaluation}

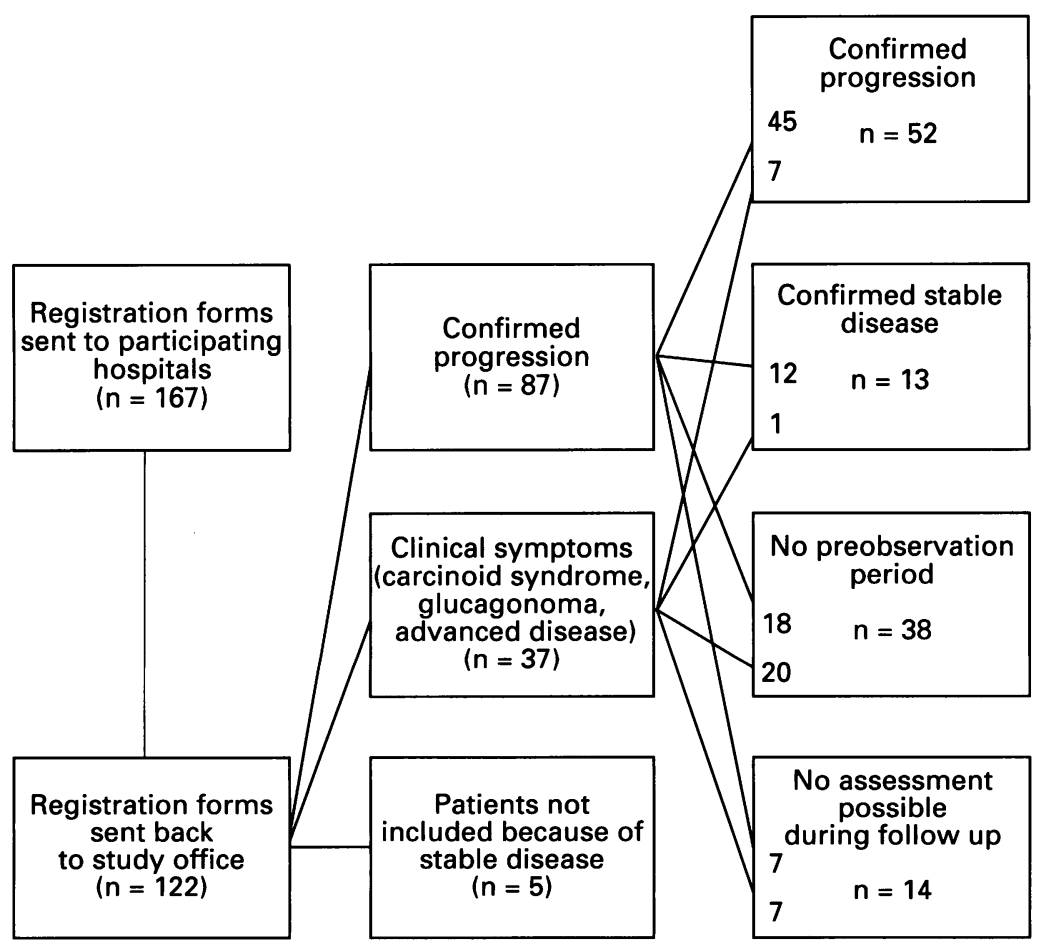

Figure 1: Recruitment of patients. Retrospective evaluation of computed tomography results in significant deviations from the initial interpretation by participating hospitals.

\section{Results}

A total of 122 of 167 registration forms were returned to the study office. The difference resulted from doctors deciding against treatment with octreotide and from patients refusing to participate in the trial mainly because of the need of three daily self injections. As judged by the participating centres 87 of 122 patients showed computed tomography confirmed tumour progression and 37 patients have been included in the trial because of the severity of the associated endocrine syndrome. Stable disease not requiring antiproliferative treatment has been reported in five patients. As random review of computed tomography performed at our institution showed discrepancies with the statements of participating hospitals concerning tumour progression before treatment every tomogram of patients included into the study was re-evaluated at our institution. This evaluation was performed by a radiologist not aware of the response criteria formulated in the study protocol. Participating hospitals were, therefore, asked to send tomogram copies to the study office. As Fig 1 shows, confirmed tumour progression was confirmed only in 52 patients, stable disease over six months was diagnosed in 13 patients whereas no confirmed preobservation period was assessed in 38 patients mainly because of poor computed tomography. The last two groups of patients were not excluded from further follow up as subsequent tomograms could satisfactorily be evaluated. Nineteen patients have been excluded from further follow up because of poor records in 14 and stable disease according to the decision of the participating hospitals in five patients. Therefore, the final study sample consisted of 103: fifty two patients with confirmed tumour progression, 13 patients with confirmed stable disease before onset of octreotide therapy, and 38 patients with no information on pre-entry tumour growth available.

Tables I and II summarise patients' characteristics and the distribution of functional and non-functional tumours within the three subgroups according to tumour growth before start of octreotide treatment. Consistent with

TABLE II Distribution of functional and non-functional tumours within the three subgroups of patients

\begin{tabular}{|c|c|c|c|c|}
\hline & \multicolumn{4}{|c|}{ Tumour growth before octreotide } \\
\hline & Progression & $\begin{array}{l}\text { Stable } \\
\text { disease }\end{array}$ & Unknown & Total \\
\hline \multicolumn{5}{|c|}{ Functional tumours } \\
\hline Insulinoma & & 1 & & 1 \\
\hline Glucagonoma & 3 & & 1 & 4 \\
\hline Gastrinoma & 8 & & 3 & 11 \\
\hline \multicolumn{5}{|c|}{ Carcinoid syndrome originating from: } \\
\hline Small intestine & 14 & 3 & 17 & 34 \\
\hline Pancreas & 1 & 1 & 1 & 3 \\
\hline Stomach & 1 & & & 1 \\
\hline Colon & 1 & & & 1 \\
\hline Lung & 1 & & & 1 \\
\hline Unknown & 2 & 1 & 5 & 8 \\
\hline Total & 31 & 6 & 27 & 64 \\
\hline \multicolumn{5}{|c|}{ Non-functional tumours originating from: } \\
\hline Small intestine & 3 & 3 & 3 & 9 \\
\hline Pancreas & 8 & 3 & 4 & 15 \\
\hline Stomach & 2 & 1 & 2 & \\
\hline Colon/rectum & 2 & & $\overline{1}$ & 3 \\
\hline Lung & 1 & & 1 & 2 \\
\hline Unknown & 5 & & & 5 \\
\hline Total & 21 & 7 & 11 & 39 \\
\hline
\end{tabular}


TABLE III Numbers and reasons for drop out during the trial (total study sample=103)

\begin{tabular}{|c|c|c|c|c|c|}
\hline & \multicolumn{3}{|c|}{ Reasons for drop out } & \multirow[b]{2}{*}{$\begin{array}{l}\text { Total } \\
\text { drop outs }\end{array}$} & \multirow{2}{*}{$\begin{array}{l}\text { Patients } \\
\text { remaining } \\
\text { in the study }\end{array}$} \\
\hline & $\begin{array}{l}\text { Tumour } \\
\text { progress }\end{array}$ & Death & $\begin{array}{l}\text { Other } \\
\text { reasons }\end{array}$ & & \\
\hline \multicolumn{6}{|l|}{ Month } \\
\hline$<=1$ & - & 4 & 3 & 7 & 96 \\
\hline $1-3$ & 3 & 4 & 2 & 9 & 87 \\
\hline $3-6$ & 2 & 3 & 3 & 8 & 79 \\
\hline $6-9$ & 4 & 5 & 2 & 11 & 68 \\
\hline $9-12$ & 3 & 4 & 2 & 9 & 59 \\
\hline Total & 12 & 20 & 12 & 44 & \\
\hline
\end{tabular}

the variable natural history of these tumours, the median time from diagnosis of malignancy to study entry was 17 months with a range of up to 251 months. Forty seven of 103 patients had a Karnofsky performance score below 80 . Among the 64 patients with functional tumours, 48 have been classified as carcinoids with the respective clinical syndrome, 11 as gastrinoma, four as glucagonoma, and only one as insulinoma. The small intestine was the site of the primary tumour in 34 of 48 patients with carcinoid syndrome. Thirty nine patients had non-functional tumours of which most originated from the pancreas and the small intestine. Somatostatin receptors have been estimated in 25 patients either by Octreoscan, by in vitro autoradiography or by both methods. With the exception of one insulinoma and one non-functional tumour all tumours were receptor positive.

Table III summarises the number and reasons for drop outs and death. Only 59 $(57 \cdot 3 \%)$ of 103 patients could be followed up over the entire study period of 12 months, as 20 died during the trial and 12 dropped out because of tumour progression. The total number of deaths within 12 months increased to $31(30 \cdot 1 \%)$ as 11 patients died after drop out from the trial because of continuous tumour progression.

\section{Hormonal response}

Of the 48 patients with carcinoid syndrome information on the effect of octreotide on flushing was available in 40 patients and diarrhoea in 28 patients (Table IV). Less than $36 \%$ of patients reported unchanged or even worsening symptoms during octreotide treatment whereas most showed impressive symptomatic improvement. Hormone secretion (serum gastrin, 5-HIAA) was influenced less impressively and improved by more than $50 \%$ in only

TABLE IV Effect of octreotide on flushing, diarrhoea, and hormone secretion in patients with functional endocrine GEP tumours

\begin{tabular}{|c|c|c|c|c|}
\hline \multirow[b]{2}{*}{ Symptoms } & \multicolumn{4}{|l|}{ Response } \\
\hline & $\begin{array}{l}\text { Normalisation } \\
\text { No (\%) }\end{array}$ & $\begin{array}{l}\text { Improvement }>50 \% \\
\text { No (\%) }\end{array}$ & $\begin{array}{l}\text { No change } \\
\text { No (\%) }\end{array}$ & $\begin{array}{l}\text { Worse } \\
\text { No (\%) }\end{array}$ \\
\hline \multicolumn{5}{|l|}{ Diarrhoea ${ }^{\star}$} \\
\hline $\begin{array}{l}\text { Month } 3(n=28) \\
\text { Month } 12(n=20)\end{array}$ & $\begin{array}{l}9(32 \cdot 1) \\
9(45 \cdot 0)\end{array}$ & $\begin{array}{l}9(32 \cdot 1) \\
8(40 \cdot 0)\end{array}$ & $\begin{array}{l}6(21 \cdot 5) \\
1(5 \cdot 0)\end{array}$ & $\begin{array}{l}4(14 \cdot 3) \\
2(10 \cdot 0)\end{array}$ \\
\hline \multicolumn{5}{|l|}{ Flushing ${ }^{\star}$} \\
\hline $\begin{array}{l}\text { Month } 3(n=40) \\
\text { Month } 12(n=27)\end{array}$ & $\begin{array}{l}14(35) \\
12(44 \cdot 4)\end{array}$ & $\begin{array}{l}16(40) \\
11(40 \cdot 8)\end{array}$ & $\begin{array}{l}9(22 \cdot 5) \\
3(11 \cdot 1)\end{array}$ & $\begin{array}{l}1(2 \cdot 5) \\
1(3 \cdot 7)\end{array}$ \\
\hline \multicolumn{5}{|l|}{ Hormone secretiont } \\
\hline $\begin{array}{l}\text { Month } 3(n=61) \\
\text { Month } 12(n=39)\end{array}$ & $\begin{array}{l}7(11 \cdot 5) \\
2(5 \cdot 1)\end{array}$ & $\begin{array}{l}18(29 \cdot 5) \\
11(28 \cdot 2)\end{array}$ & $\begin{array}{l}21(34 \cdot 4) \\
15(38 \cdot 5)\end{array}$ & $\begin{array}{l}15(24 \cdot 6) \\
11(28 \cdot 2)\end{array}$ \\
\hline
\end{tabular}

^Patients with carcinoid syndrome, tpatients with functional tumours.
$33.3 \%$ of 39 patients during 12 months of treatment.

\section{Tumour response to octreotide}

Table V summarises the effect of octreotide on tumour growth in $\mathbf{5 2}$ patients with confirmed progression before treatment. No objective tumour regression could be seen in this group of patients. However, 14 patients experienced stable disease three months after start of octreotide treatment. Of these 14 patients stable disease continued until month 12 in seven patients whereas four patients experienced further tumour progression and three died. In five of 30 patients with ongoing tumour progression defined as an increase in tumour growth by more than $25 \%$ between start of treatment and month 3, tumour standstill lasting for at least three months occurred between month 3 and 6 . Therefore, stabilisation of the disease occurring in 19 of 52 patients $(36.5 \%)$ with confirmed tumour progression before octreotide treatment was the most favourable therapeutic effect. Figure 2 shows the length of time from stable disease to tumour progression in these 19 patients. After 12 months stable disease continued in 12 patients, declined after 24 months to nine patients, and after 36 months to five patients. The median duration of stable disease was 18 months.

As the results of the study depended on the evaluation of response, we studied in this subgroup the association of tumour growth inhibition and specific characteristics of patients' tumours (Table VI). Patients with a good Karnofsky performance score responded significantly better to octreotide than those with a low performance score. There was no strong evidence that any other specific characteristic made a patient more responsive or resistant to octreotide treatment. Although the numbers were small, there was a tendency of endocrine tumours originating from the small intestine and of patients with carcinoid syndrome to respond better to octreotide treatment compared with pancreatic endocrine tumours and non-functional tumours. The ability of octreotide to improve flushing and diarrhoea in patients with carcinoid syndrome or to suppress hormone release failed to predict tumour growth inhibition.

In 13 patients stable disease for at least three months before octreotide was confirmed by computed tomography. None of these patients died during octreotide treatment and follow up for 12 months. Also in this subgroup no patient experienced tumour regression (Table VII). After three months of treatment stable disease continued in $10(76.9 \%)$ and after 12 months in seven $(53.8 \%)$ patients. No evaluation was possible in three patients because of unsatisfactory computed tomography in two patients and discontinuation of treatment during the first month in one patient.

Therefore, according to the study protocol no patient within this subgroup responded to octreotide with respect to inhibition of tumour growth. 
TABLE V Effect of octreotide on tumour growth in 52 patients with confirmed progression before treatment

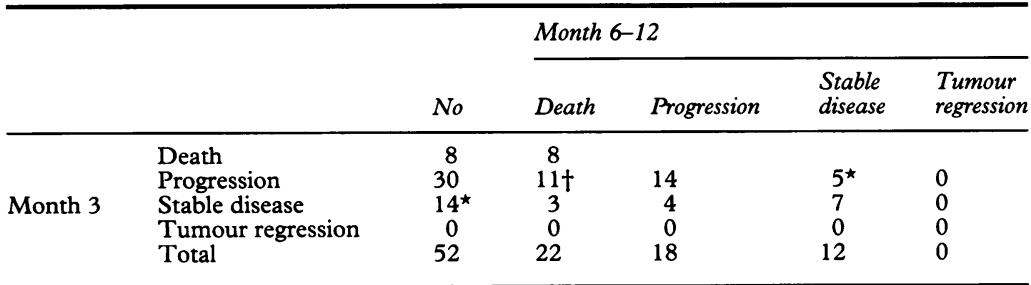

${ }^{\star}$ Response to octreotide occurred in 19 patients according to the study protocol, fone death from heart infarction.
TABLE VI Inhibition of tumour growth according to patients' characteristics $(n=52)$

\begin{tabular}{|c|c|c|c|}
\hline Characteristics & $\begin{array}{l}\text { No of } \\
\text { patients }\end{array}$ & $\begin{array}{l}\text { No with } \\
\text { objective growth } \\
\text { inhibition (\%) }\end{array}$ & $\stackrel{p}{\text { Value }}$ \\
\hline \multicolumn{4}{|l|}{ Sex } \\
\hline Male & 34 & $14(41 \cdot 2)$ & \multirow{2}{*}{0.514} \\
\hline Female & 18 & $5(27 \cdot 8)$ & \\
\hline \multicolumn{4}{|l|}{ Age (y) } \\
\hline$<60$ & 37 & $12(32 \cdot 4)$ & \multirow[t]{2}{*}{0.517} \\
\hline \multicolumn{3}{|l|}{ Karnofsky Index } & \\
\hline $\begin{array}{l}<80 \\
\geqslant 80\end{array}$ & $\begin{array}{l}25 \\
25\end{array}$ & $\begin{array}{r}5(20.0) \\
13(52 \cdot 0)\end{array}$ & 0.039 \\
\hline \multirow{2}{*}{\multicolumn{4}{|c|}{ Tumour type }} \\
\hline Gastrinoma & & & \multirow{3}{*}{$0 \cdot 122$} \\
\hline Carcinoid syndrome & 20 & $11(55 \cdot 0)$ & \\
\hline $\begin{array}{l}\text { Non-functional tumour } \\
\text { Glucagonoma }\end{array}$ & 21 & $5(23 \cdot 8)$ & \\
\hline \multicolumn{4}{|l|}{ Origin of primary } \\
\hline Small intestine & 19 & $10(52 \cdot 6)$ & \multirow[t]{2}{*}{$0 \cdot 229$} \\
\hline Pancreas & 18 & $5(27 \cdot 8)$ & \\
\hline \multicolumn{4}{|l|}{ Somatostatin receptors } \\
\hline Present & 13 & $8(61 \cdot 5)$ & \\
\hline \multicolumn{4}{|l|}{ Previous chemotherapy } \\
\hline Yes & 20 & $5(25 \cdot 0)$ & \multirow[t]{2}{*}{$0 \cdot 285$} \\
\hline No & 32 & $14(43 \cdot 8)$ & \\
\hline \multicolumn{4}{|l|}{ Improvement of flushing ${ }^{\star}$} \\
\hline Ŷes & 12 & $9(75 \cdot 0)$ & \multirow[t]{2}{*}{0.547} \\
\hline \multirow{2}{*}{\multicolumn{4}{|c|}{ Improvement of diarrhoea }} \\
\hline & & & \\
\hline Y̌es & 7 & $4(57 \cdot 1)$ & \multirow[t]{2}{*}{$1 \cdot 0$} \\
\hline $\begin{array}{l}\text { No } \\
\text { Hormone suppression* }\end{array}$ & 5 & $3(60 \cdot 0)$ & \\
\hline \multicolumn{4}{|l|}{ Hormone suppression ${ }^{\star}$} \\
\hline $\begin{array}{l}\text { Yes } \\
\text { No }\end{array}$ & 2 & $1(50 \cdot 0)$ & $1 \cdot 0$ \\
\hline No & 14 & $9(04.5)$ & \\
\hline
\end{tabular}

^Carcinoid syndrome only. In one patient evaluation of response was not possible because of non-fatal unexplained septicaemia during the first two weeks of treatment and subsequent discontinuation of treatment.

In 28 patients with tumour progression during $200 \mu \mathrm{g}$ octreotide thrice daily treatment dose was increased to $500 \mu \mathrm{g}$ thrice daily: in 15 of 52 patients with tumour progression before octreotide, in three of 13 patients with stable disease, and in 10 of 38 patients with no information on spontaneous tumour growth before octreotide. Increase of octreotide dose to $500 \mu \mathrm{g}$ thrice daily was performed in 11 patients at month 3,12 patients at month 6 , two patients at month 9 , and three patients at month 12 for at least six subsequent months. In 27 patients increase of octreotide did not change tumour growth behaviour seen with the lower dose. Only in one patient with ongoing tumour progression at month 3 tumour standstill occurred lasting until the observation period of 12 months.

Toxicity

Octreotide was well tolerated. None of the side

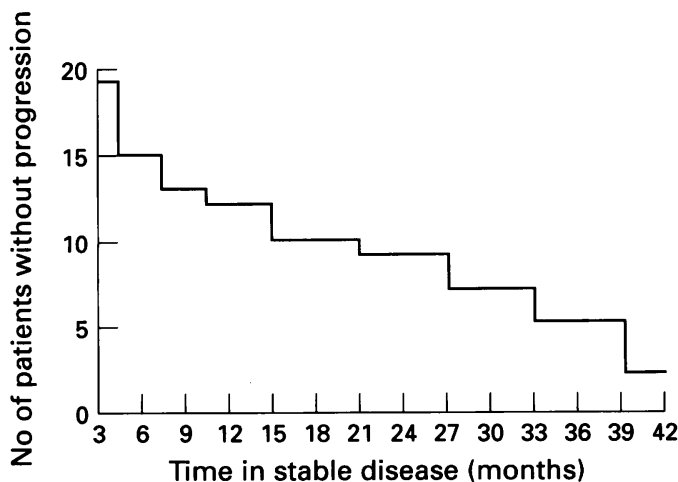

Figure 2: Length of time to disease progression in 19 patients with inhibition of tumour growth for at least three months. effects listed in Table IX required discontinuation of treatment with the exception of unexplained, non-fatal septicaemia seen in one patient during the first two weeks of treatment. Steatorrhoea measured by faecal fat excretion developed in three of 28 patients and new gall stones were detected in two patients.

\section{Discussion}

Previous trials with octreotide have concentrated on the biochemical and symptomatic effect of the drug in patients with metastatic endocrine GEP tumours and have been confirmed by the presented data. In some of these studies tumour growth during octreotide treatment had been evaluated and the results obtained from 94 patients summarised in a recent NIH report. ${ }^{22}$ However, patients included in this report had not been standardised with respect to tumour growth before octreotide treatment, its dose, and criteria to assess tumour growth inhibition. The German Sandostatin multicentre phase II trial with 103 patients, of whom in 52 patients a final assessment of the effect on tumour growth was possible, provides further evidence that octreotide indeed inhibits tumour growth. Stabilisation of the disease after computed tomography confirmed tumour progression before octreotide was the most favourable result. Tumour shrinkage as shown in a few case reports earlier ${ }^{64-38}$ did not occur in this prospective trial. The presented results focus on the importance of the confirmation of spontaneous tumour growth before the onset of treatment and rely only on computed tomography interpretation by a reference centre in prospective multicentre trials. Our experience based on retrospective computed tomography evaluation shows that deviations in the 
TABLE VII Effect of octreotide on tumour growth in 13 patients with confirmed stable disease before treatment

\begin{tabular}{llrllll}
\hline & \multicolumn{5}{c}{ Month 6-12 } \\
\cline { 5 - 7 } \cline { 5 - 6 } & & No & Progression & $\begin{array}{l}\text { Stable } \\
\text { disease }\end{array}$ & $\begin{array}{l}\text { Tumour } \\
\text { regression }\end{array}$ & $\begin{array}{l}\text { No evaluation } \\
\text { possible }\end{array}$ \\
\hline \multirow{4}{*}{ Month 3} & No evaluation possible* & 1 & & & & 1 \\
& Progression & 2 & 2 & & 0 & 1 \\
& Stable disease & 10 & 2 & 7 & 0 & 1 \\
& Tumour regression & 0 & 0 & 0 & 0 & 0 \\
& Total & 13 & 4 & 7 & 0 & 2 \\
\hline
\end{tabular}

$\star$ Because of discontinuation of treatment during the first month.

interpretation of tomograms arise mainly from poor image quality, greater than $0.8 \mathrm{~cm}$ scan intervals, and no or poor intravenous contrast enhancement. Therefore, we did not regard patients as 'drop out' if retrospective evaluation at our institution could not confirm the assessment of tumour growth as judged by the participating hospitals and an unequivocal later follow up and evaluation of tomograms in these patients was possible. The results of this study are based on either unequivocal tumour progression or stable disease before octreotide treatment whereas patients with poor computed tomography evidence of tumour growth before octreotide treatment have been included in the subgroup of patients with no information on spontaneous tumour growth before treatment. Whether magnetic resonance tomography may be preferable to computed tomography as the reference imaging technique in future multicentre studies has not been evaluated yet, but recent studies show that magnetic resonance imaging is very sensitive for detecting metastatic lesions of endocrine tumours of the liver. ${ }^{42} \mathrm{We}$ observed 19 of 52 patients corresponding to a response rate of $36.5 \%$, in whom tumour growth stabilised during treatment. The responders originated from the subgroup with computed tomography confirmed tumour progression before octreotide. Median duration of disease stabilisation lasted for 18 months. During the three years of continuous octreotide treatment, five of 19 patients remained in stable disease. The data on these 52 patients are worse than the $52 \%$ responders reported by Saltz et al in 32 patients with maintainable stabilisation of tumour growth for a minimum of two months. ${ }^{23}$ Our data do not permit any conclusions with respect to a survival advantage as suggested by Saltz et $a l^{23}$ but the beneficial effect of octreotide is at least in some patients longlasting. The presented results do not exclude the possibility that at least short lasting

TABLE VIII Effect of octreotide on tumour growth in 38 patients with no information on spontaneous tumour growth before treatment

\begin{tabular}{|c|c|c|c|c|c|c|c|}
\hline & & \multirow[b]{2}{*}{ No } & \multicolumn{5}{|c|}{ Month 6-12 } \\
\hline & & & Death & Progression & $\begin{array}{l}\text { Stable } \\
\text { disease }\end{array}$ & $\begin{array}{l}\text { Tumour } \\
\text { regression }\end{array}$ & $\begin{array}{l}\text { No } \\
\text { evaluation } \\
\text { possible }\end{array}$ \\
\hline Month 3 & $\begin{array}{l}\text { No evaluation possible } \\
\text { Death } \\
\text { Progression } \\
\text { Stable disease } \\
\text { Tumour regression } \\
\text { Total }\end{array}$ & $\begin{array}{r}1 \\
2 \\
15 \\
20 \\
0 \\
38\end{array}$ & $\begin{array}{r}2 \\
6 \\
2 \\
0 \\
10\end{array}$ & $\begin{array}{r}8 \\
5 \\
0 \\
13\end{array}$ & $\begin{array}{r}0 \\
13 \\
0 \\
13\end{array}$ & $\begin{array}{l}0 \\
0 \\
0 \\
0\end{array}$ & $\begin{array}{l}1 \\
1 \\
2\end{array}$ \\
\hline
\end{tabular}

$\star$ Because of discontinuation of treatment during the first month.
TABLE IX Side effects seen during octreotide treatment ${ }^{\star}$

\begin{tabular}{llc}
\hline & Observed & Study population \\
\hline Diarrhoea & 34 & 96 \\
Flatulence & 27 & 96 \\
Pain at injection site & 27 & 96 \\
Vomiting & 11 & 96 \\
Steatorrhoea & 8 & 28 \\
Hyperglycaemia & 3 & 80 \\
Gall stonest & 2 & 96 \\
Septicaemia & 1 & 103 \\
\hline
\end{tabular}

* Symptoms related to the underlying disease have been excluded, tin addition to these two patients gall stones have been seen in another two patients before octreotide treatment.

stabilisation of tumour growth during octreotide treatment after preceding tumour progression mirrors phases of spontaneous tumour growth behaviour and could also occur without treatment. We do not believe, however, that an overall response rate of $36 \%$ justifies this assumption.

Within the subgroup of 13 patients with stable disease before octreotide we found only four, in whom stable disease changed to tumour progression: in two at month 3 and in two during the subsequent nine months. Therefore, in $53.8 \%$ stable disease continued and, noteworthy, no patient within this subgroup died. Therefore, this trial does not exclude the possibility that patients with stable disease before octreotide may profit from the drug by extending the interval of stable disease.

With the exception of patients with a good Karnofsky score responding significantly better to octreotide than those with a low performance score no further association of antiproliferative response and specific characteristics of patients' tumours could be ascertained. Age, previous chemotherapy, symptomatic response to or hormone suppression by octreotide did not predict inhibition of tumour growth. As endocrine response and tumour size have not been found to be related, different cellular pathways may exert these effects. The presence of somatostatin receptors as defined by in vitro autoradiography using labelled octreotide as ligand ${ }^{40}$ or Octreoscan scintigraphy ${ }^{41}$ was also not predictive although $61.5 \%$ of receptor positive tumours responded with tumour growth inhibition. Currently, we are investigating additional somatostatin receptor subtypes ${ }^{43} 44$ on preserved tumour specimens and their relation to growth inhibition. As shown in Table VI, there was a tendency of tumours originating from the small intestine and of patients with carcinoid syndrome to respond better to octreotide compared with pancreatic tumours and non-functional tumours.

Mortality within our study sample was considerably high and may reflect the Karnofsky performance score of 80 and below in 47 of 103 patients at study entry. Obviously, octreotide is unable to prevent fatal outcome in an advanced state of the disease.

We conclude that the results of this prospective phase II trial are strong enough to generate the hypothesis that octreotide inhibits tumour growth in patients with metastatic endocrine GEP tumours. Further randomised trials based on a more homogeneous group of tumours and with survival time as end point 
will be needed to prove this hypothesis, to identify those subgroups of tumours responding to octreotide with inhibition of tumour growth, and to examine even higher doses of octreotide. Although there is some information from patients with malignant neuroendocrine tumours taking octreotide doses exceeding $5 \mathrm{mg} /$ daily 4546 showing that circulating hormone concentrations not normalised with $600 \mu \mathrm{g}$ octreotide daily responded to increasing doses, there are currently no data available to suggest that higher doses of octreotide than those used in this study should be recommended for antiproliferative purposes. Our data on patients with $500 \mu \mathrm{g}$ octreotide thrice daily do not support the assumption that higher doses of octreotide are superior as only one of 28 patients with tumour progression during $200 \mu \mathrm{g}$ thrice daily experienced stable disease with $500 \mu \mathrm{g}$ thrice daily. However, this question should be considered in further studies with even higher doses. According to the data of this trial, special interest should also be directed in future studies to patients with stable disease before octreotide treatment. As long as no data from prospective and placebo controlled studies are available, this expensive drug cannot be recommended as antiproliferative treatment to this last subgroup of patients.

The authors thank Mr V Wiederholdt at Sandoz AG Nürnberg for cooperation in the provision of Sandostatin. Authors are, in
addition, indebted to Dr H Lenze and Dr M Prinz for assistance in data management, Dr E Slater for editing the manuscript, in data management, $\mathrm{Dr} E$ Slater for editing the
and Mrs $\mathrm{H}$ Flügel-Michel for typing the manuscript.

A full list of participating hospitals is available from the authors.

1 Arnold $\mathrm{R}$. Therapeutic strategies in the management of endocrine GEP tumours. Eur f Clin Invest 1990; 20 (suppl 1): $82-90$.

2 Ch'ng JL, Anderson JV, Williams SJ, Carr DH, Bloom SR Remission of symptoms during long-term treatment of metastatic pancreatic endocrine tumours with long-acting somatostatin analogue. $B M \mathcal{F} 1985$; ii: $981-2$.

3 Kvols LK, Buck M, Moertel ChG, Schutt AJ, Rubin J, O'Connell MJ, et al. Treatment of metastatic islet cell carcinoma with a somatostatin analogue (SMS 201-995) Ann Intern Med 1987; 107: 162-8.

4 Maton PN, Gardner JD, Jensen RT. Use of long-acting somatostatin analogue SMS 201-995 in patients with pancreatic islet-cell tumours. Dig Dis Sci 1989; 34 (suppl): 285-91.

5 Buchanan $\mathrm{KD}$. Effects of sandostatin on neuro-endocrine tumours of the gastrointestinal system. Recent Result tumours of the gastrointestinal

6 Creutzfeldt W, Bartsch HH, Jacubaschke U, Stöckmann F. Treatment of gastrointestinal endocrine tumours with interferon-alpha and octreotide. Acta Oncol 1991; 30 529-36.

7 Arnold $R$, Neuhaus $C h$, Benning R, Schwerk WB Trautmann ME, Joseph $\mathrm{K}$, et al. Somatostatin analog sandostatin and inhibition of tumour growth in patients with metastatic endocrine gastroenteropancreatic tumours. World $\mathcal{F}$ Surg 1993; 17: 511-9.

8 Rothmund M, Stinner B, Arnold R. Endocrine pancreatic carcinoma. Eur $\mathcal{F}$ Surg Oncol 1991; 17: 191-9.

9 Allison DJ, Jordan H, Hennessy O. Therapeutic embolization of the hepatic artery: a review of 75 procedures. Lancet 1985; i: 595-9.

10 Carrasco $\mathrm{CH}$, Charnsangavej $\mathrm{Ch}$, Ajani J, Samaan NA, Richli W, Wallace $S$. The carcinoid syndrome: palliation by hepatic artery embolization. Am $\mathcal{F}$ Radiol 1986; 147: $149-54$

11 Moertel CG, Hanley JA, Johnson LA. Streptozotocin alone compared with streptozotocin plus fluorouracil in the treatment of advanced islet-cell carcinoma. $N$ Engl $\tilde{F} \mathrm{Med}$ 1980; 303: 1189-94.

12 Sridhar KS, Holland JF, Brown JC, Cohen JM, Ohnuma T. Doxorubicin plus cisplatin in the treatment of apudomas. Cancer 1985; 55: 2634-7.

13 Kvols LK, Buck M. Chemotherapy of endocrine malignancies: a review. Semin Oncol 1987; 14: 343-83.

14 Von Schrenck T, Howard JM, Doppman JL, Norton JA, Maton PN, Smith FP, et al. Prospective study of chemotherapy in patients with metastatic gastrinoma. Gastroenterology 1988; 94: 1326-34.
15 Moertel CG, Kvols LK, O'Connell MJ, Rubin J. Treatment of neuroendocrine carcinomas with combined etoposide and cisplatin. Evidence of major therapeutic activity in the anaplastic variants of these neoplasms. Cancer 1991; 68: 227-32.

16 Moertel CG, Lefkopoulo M, Lipsitz S, Hahn RG, Klaassen D. Streptozotocin-doxorubicin, streptozotocinfluorouracil, or chlorozotocin in the treatment of advanced islet-cell carcinoma. $N$ Engl f Med 1992; 326: 519-23.

17 Makowka L, Tzakis AG, Mazzaferro V, Teperman L, Demetris AJ, Iwatsuki S, et al. Transplantation of the live for metastatic endocrine tumours of the intestine and pancreas. Surg Gynecol Obstet 1989; 168: 107-11.

18 Johnson LA, Lavin P, Moertel CG, Weiland L, Dayal Y. Carcinoids: the association of histologic growth pattern and survival. Cancer 1983; 51: 882-9.

19 Öberg K, Funa K, Alm G. Effects of leucocyte interferon on clinical symptoms and hormone levels in patients with mid-gut carcinoid tumours and carcinoid syndrome. with mid-gut carcinoid tumours and

20 Öberg K, Norheim I, Lind E, Alm G, Lundquist G, Wide $\mathrm{L}$, et al. Treatment of malignant carcinoid tumours with human leucocyte interferon: long-term results. Cancer Treat Rev 1986; 11: 1297-304.

21 Smith DB, Scarffe JH, Wagstaff J, Johnston RJ Phase II trial of rDNA alfa $2 b$ interferon in patients with malignant carcinoid tumour. Cancer Treat Rep 1987; 7: 1265-6.

22 Gordon $\mathrm{Ph}$. NIH Conference: Somatostatin and somatostatin analogue (SMS 201-995) in treatment of hormonesecreting tumours of the pituitary and gastrointestinal tract and non-neoplastic diseases of the gut. Ann Intern tract and non-neoplastic

23 Saltz L, Trochanowsky G, Buckley M, Heffernan B, Niedzwicki D, Tao Y, Kelsen D. Octreotide as an antineoplastic agent in the treatment of functional and nonfunctional neuroendocrine tumours. Cancer 1993; 72 244-8.

24 Hanssen LE, Schrumpf E, Kolbenstredt AN, Tausjo J, Dolva LO. Recombinant alpha-2 interferon with or without hepatic artery embolization in the treatment of midgut carcinoid tumours - a preliminary report. Acta Oncol 1989; 28: 439-43.

25 Joensuu H, Kätka K, Kujari H. Dramatic response of a metastatic carcinoid tumour to a combination of interferon and octreotide. Acta Endocrinol (Copenh) 1992; 126: 184-5.

26 Nold R, Frank M, Kajdan U, Trost U, Klose $\mathbf{K H}$, Arnold R. Kombinierte Behandlung metastasierter endokriner Tumoren des Gastrointestinaltraks mit Octreotid und Interferon-Alpha. $Z$ Gastroenterol 1994; 32 193-7.

27 Kvols LK, Moertel CG, O'Connell MJ, Schutt AJ, Rubin J, Hahn RG. Treatment of the malignant carcinoid syndrome. Evaluation of a long-acting somatostatin analogue. N Engl f Med 1986; 315: 663-6.

28 Vinik A, Moattari AR. Use of somatostatin analogue in management of carcinoid syndrome. Dig Dis Sci 1989; 34 (suppl): 14-27S

29 Ruskoné A, René E, Chayvialle JA, Bonin N, Pignal F, Kremer M, et al. Effect of somatostatin on diarrhoea and on small intestinal water and electrolyte transport in a patien with pancreatic cholera. Dig Dis Sci 1982; 27: 459-66.

30 Maton PN, O'Dorisio ThM, Howe BA, McArthur KE, Howard JM, Cherner JA, et al. Effect of long-acting somatostatin analogue (SMS 201-995) in a patient with pancreatic cholera. $N$ Engl $\mathcal{F}$ Med 1985; 312: 17-21.

31 Santangelo WC, O'Dorisio ThM, Kim JG, Severino G, Krejs G. Pancreatic cholera syndrome: effect of a synthetic somatostatin analogue on intestinal water and ion transport. Ann Intern Med 1985; 103: 363-7.

32 Boden G, Ryan IG, Eisenschmidt BL, Shelmet J, Owen OE. Treatment of inoperable glucagonoma with longacting somatostatin analogue SMS 201-995. $N$ Engl $f$ Med 1986; 314: 1686-9.

33 Evers BM, Parekh D, Townsend CM, Thompson JC. Somatostatin and analogues in the treatment of cancer. A review. Ann Surg 1991; 213: 190-8.

34 Kraenzlin ME, Ch'ng JC, Wood SM, Bloom SR. Can inhibition of hormone secretion be associated with endocrine tumour shrinkage? Lancet 1983; ii: 1501-4.

35 Kraenzlin ME, Ch'ng JC, Wood SM, Carr DJ. Long-term treatment of a VIPoma with somatostatin analogue resulting in remission of symptoms and possible shrinkage of metastases. Gastroenterology 1985; 88: 185-7.

36 Clements D, Elias E. Regression of metastatic VIPoma with somatostatin analogue SMS 201-995. Lancet 1985; i: 874-5

37 Shepherd J, Senator GB. Regression of liver metastases in patient with gastrin-secreting tumour treated with SMS 201-995. Lancet 1986; ii: 574

38 Wiedenmann B, Räth U, Rädsch R, Becker F, Kommerell $B$. Tumour regression of an ileal carcinoid under the treatment with the somatostatin analogue SMS 201-995. Klin Wochenschr 1988; 66: 75-7.

39 Capella C, Heitz PhU, Höfler H, Solcia E, Klöppel G. Revised classification of neuroendocrine tumours of the lung, pancreas and gut. Digestion 1994; 55 (suppl 3): 11-23.

40 Bruns Ch, Dietl MM, Palaccos JM, Pless J. Identification and characterization of somatostatin receptors in neonatal rat long bones. Biochem f 1990; 265: 39-45.

41 Joseph K, Stapp J, Reinecke J, Höffken H, Benning $R$, Neuhaus Ch, et al. Rezeptorszintigraphie bei endokrinen 
gastroentero-pankreatischen Tumoren. Wochenschr 1992; 117: 1025-8.

42 Orbuch RV, Metz DC, et al. Imaging for pancreatic endocrine tumour localization: recent advances. In: Mignon $M$ Jensen RT, eds. Endocrine tumours of the pancreas. Basel: Karger, 1995: 23: 268-81.

43 Reubi JC. Somatostatin receptors in the gastrointestinal tract in health and disease. Yale $\mathcal{F}$ Biol Med 1992; 65: 505-18.
44 Lewin MJ. The somatostatin receptor in the GI tract. Ann Rev Physiol 1992; 54: 455-68.

45 Deguchi H, Deguchi K, Tsukada T, Murashima S, Iwasaki $\mathrm{E}$, Tsuda $\mathrm{M}$, et al. Long-term survival in a patient with malignant carcinoid treated with high-dose octreotide. Intern Med 1994; 31: 100-2.

46 Anthony LB, Winn SD, Johnson DH, Oates JA. Chronic high dose octreotide in neuroendocrine neoplasms. Ann Oncol 1994; 5 (suppl 5): A267. 